\section{Antes do Próximo, Um Complemento ao Editorial Anterior}

$\mathrm{U}$ ma vez pronto e analisado o material anteriormente pendente, aproveito a seqüência e apresento neste editorial um complemento à listagem dos autores mais profícuos da revista, agora incluindo a primeira fase ou primeiro período da revista: de 1951 a 1972 . Lembro que, por motivos apenas didáticos, dividi esta história dos ABE\&M em dois períodos distintos: os anos iniciais, que vão desde sua criação em Agosto de 1951 até sua forçada interrupção por 6 anos, em 1972, e aqueles que eu chamei de "anos modernos", que vão desde sua ressureição em 1978 até os dias de hoje. Temos, no primeiro período, exatos 20 anos de produção, interrompidos apenas durante o ano de 1956, quando da morte do criador da revista, Waldemar Berardinelli. No segundo, são computados 23 anos de publicação ininterrupta, até o final de 2001.

Apenas por praticidade, inverti a ordem cronológica da análise desse material, e no editorial anterior, apresentei os colaboradores mais assíduos da segunda fase da revista. Agora, voltamos às origens para relembrar nossos colegas do passado (alguns ainda produzindo eficientemente) e mostrar os colaboradores de então.

$\mathrm{Na}$ tabela 1. encontra-se a listagem ou ranking dos colaboradores mais participativos da primeira era da revista e, mais adiante, após mesclarmos todas as autorias desde 1951 até o final de 2001, apresentamos uma listagem final oficial dos 15 maiores e mais assíduos colaboradores da revista ( "ABE\& $M$ 's Top 15 ”), por ordem de quantidade de autorias.

\section{OS AUTORES MAIS PROFÍCUOS DA PRIMEIRA FASE DOS ABE\&M (1951-1972)}

Mais uma vez, relembro aos leitores que não entendam este assunto como uma competição, mas uma homenagem, já que não houve jamais a intenção de um concurso; apenas a verificação e comprovação estatística do número de colaborações de autores que participaram com suas contribuições na revista ao longo de sua produtiva vida científica.

Cabe também, mais uma vez, o alerta e as ressalvas mencionados no editorial anterior: por mais cuidado que tenhamos dedicado à compilação correta e precisa dos nomes dos autores (e aqui agradeço especificamente à Luciana Kater pela compilação e primeira revisão), não é impossível que alguma pequena falha possa ter passado despercebida. Mais importante - mas difícil de se avaliar -, é a possibilidade de que determinado autor possa estar sendo sub-representado pela diversidade de notações de seu nome que foram utilizadas nos vários artigos nos quais colaborou. Imprecisões deste tipo foram corrigidas sempre que detectadas. As autoras que assinavam seus trabalhos com nomes de solteira e depois, de casada (ou vice-versa), também podem ter sido subrepresentadas nesta compilação. Reafirmo o interesse em corrigir eventuais distorsões se avisado pelos interessados.

\section{editorial}

Claudio E. Kater

\author{
Disciplina de Endocrinologia, \\ Departamento de Medicina, \\ UNIFESP/EPM \\ Editor-chefe, $A B E \mathcal{O} M$
}


Quadro 1. Lista dos colaboradores mais participativos dos ABE\&M nos primeiros 20 anos da revista (1951-1972), elaborada de acordo com o número total de autorias.

\begin{tabular}{|c|c|c|c|c|c|c|c|c|}
\hline & & $\begin{array}{l}\text { Total de } \\
\text { Autorias }\end{array}$ & $\begin{array}{c}\text { Original \& } \\
\text { Comunicação }\end{array}$ & $\begin{array}{c}\text { Revisão \& } \\
\text { Atualização }\end{array}$ & $\begin{array}{l}\text { Apres.Caso } \\
\text { \& C.Especial }\end{array}$ & Editorial & $\begin{array}{l}\text { Primeiro } \\
\text { Autor (\%) }\end{array}$ & $\begin{array}{l}\text { Intervalo } \\
\text { de Tempo }\end{array}$ \\
\hline 1 & Bernardo L. Wajchenberg (SP) & 25 & 19 & 3 & 3 & 0 & $16(64,0)$ & 1959-1968 \\
\hline 2 & Waldemar Berardinelli (RJ) & 19 & 5 & 3 & 9 & 2 & $17(89,5)$ & 1951-1957 \\
\hline 3 & Fernando Ubatuba (RJ) & 18 & 14 & 4 & 0 & 0 & $15(83,3)$ & 1957-1962 \\
\hline 4 & José Schermann (RJ) & 16 & 5 & 3 & 7 & 1 & $11(68,8)$ & $1953-1970$ \\
\hline 5 & Isaac Vaissman (RJ) & 14 & 6 & 5 & 3 & 0 & $8(57,1)$ & 1961-1972 \\
\hline 5 & Dilson C. Kamel (RJ) & 14 & 6 & 4 & 4 & 0 & $2(14,3)$ & 1962-1972 \\
\hline 6 & João Gabriel H. Cordeiro (RJ) & 13 & 3 & 2 & 8 & 0 & $5(38,5)$ & 1952-1971 \\
\hline 7 & Clementino Fraga Filho (RJ) & 11 & 5 & 1 & 1 & 4 & $5(45,5)$ & 1957-1972 \\
\hline 8 & Jayme Rodrigues (RJ) & 10 & 5 & 1 & 4 & 0 & $4(40,0)$ & 1953-1970 \\
\hline 8 & Danilo de Albuquerque (RJ) & 10 & 5 & 1 & 4 & 0 & $3(30,0)$ & 1952-1971 \\
\hline 8 & José C. Cabral de Almeida (RJ) & 10 & 2 & 0 & 8 & 0 & $8(80,0)$ & 1957-1967 \\
\hline 8 & Arlette Ubatuba (RJ) & 10 & 10 & 0 & 0 & 0 & $0(0,0)$ & 1957-1962 \\
\hline 9 & Helión Póvoa Jr. (RJ) & 8 & 7 & 0 & 0 & 0 & $7(87,5)$ & $1963-1970$ \\
\hline 9 & Dejano Tavares Sobral (RJ) & 8 & 7 & 1 & 0 & 0 & $7(87,5)$ & $1959-1968$ \\
\hline 9 & Isaac Vaisman (RJ) & 8 & 3 & 2 & 3 & 0 & $4(50,0)$ & 1960-1972 \\
\hline 9 & Eli Veloso (RJ) & 8 & 3 & 4 & 1 & 0 & $3(37,5)$ & $1969-1972$ \\
\hline 10 & Antonio B. de Ulhôa Cintra (SP) & 7 & 6 & 1 & 0 & 0 & $0(0,0)$ & 1959-1966 \\
\hline
\end{tabular}

Quadro 2. Lista dos colaboradores mais participativos dos ABE\&M em todos os seus 50 anos de vida - $1951-2001$ - (e 45 anos efetivos de publicação), elaborada de acordo com o número total de autorias.

\begin{tabular}{|c|c|c|c|c|c|c|c|c|c|}
\hline & & $\begin{array}{l}\text { Total de } \\
\text { Autorias }\end{array}$ & $\begin{array}{c}\text { Original \& } \\
\text { Comunicação }\end{array}$ & $\begin{array}{c}\text { Revisão \& } \\
\text { Atualização }\end{array}$ & $\begin{array}{l}\text { Apres. Caso } \\
\& \text { C.Especial }\end{array}$ & $\begin{array}{l}\text { Perspect } \\
\text { \& Memor }\end{array}$ & Editorial & $\begin{array}{l}\text { Primeiro } \\
\text { Autor(\%) }\end{array}$ & $\begin{array}{l}\text { Intervalo } \\
\text { de Tempo }\end{array}$ \\
\hline 1 & José Gilberto H. Vieira (SP) & 70 & 53 & 7 & 8 & 1 & 1 & $22(31,4)$ & 1979-2001 \\
\hline 2 & Bernardo L. Wajchenberg (SP) & 61 & 42 & 14 & 4 & & 1 & $32(52,5)$ & 1959-2000 \\
\hline 3 & Rui M. de Barros Maciel (SP) & 41 & 32 & 1 & 4 & 1 & 3 & $7(17,1)$ & 1979-2001 \\
\hline 4 & Ewaldo Mário K. Russo (SP) & 36 & 33 & 2 & 1 & & & $6(16,7)$ & 1979-1996 \\
\hline 5 & Antonio Roberto Chacra (SP) & 34 & 24 & 6 & & 1 & 3 & $3(8,8)$ & 1979-2001 \\
\hline 5 & Geraldo A. Medeiros-Neto (SP) & 34 & 16 & 10 & 2 & 4 & 2 & $22(64,7)$ & 1963-2001 \\
\hline 6 & Bernardo Liberman (SP) & 25 & 20 & 1 & 3 & & 1 & $7(28,0)$ & 1964-1998 \\
\hline 6 & Berenice B. de Mendonça (SP) & 25 & 18 & & 6 & & 1 & $6(24,0)$ & 1979-2001 \\
\hline 6 & Armando de Aguiar Pupo (SP) & 25 & 19 & 1 & & & 5 & $9(36,0)$ & 1961-1991 \\
\hline 7 & Claudio Elias Kater (SP) $\left(^{*}\right)$ & $22^{*}$ & 14 & 2 & 3 & 1 & $2^{*}$ & $4^{*}(18,2)$ & 1979-2001 \\
\hline 8 & Ayrton Custódio Moreira (SP) & 21 & 16 & & 2 & 1 & 2 & $11(52,4)$ & 1979-1998 \\
\hline 8 & Marília de Brito Gomes (RJ) & 21 & 20 & 1 & & & & $12(57,1)$ & 1979-2001 \\
\hline 8 & Mário Vaisman (RJ) & 21 & 14 & 2 & 4 & 1 & & $4(19,0)$ & 1982-2001 \\
\hline 9 & Emílio Mattar (SP) & 20 & 13 & 1 & 5 & & 1 & $2(10,0)$ & 1957-1987 \\
\hline 9 & Alfredo Halpern (SP) & 20 & 12 & 2 & 3 & 1 & 2 & $8(40,0)$ & 1985-2000 \\
\hline 9 & Jorge Luiz Gross & 20 & 7 & 2 & 6 & 3 & 2 & $10(50,0)$ & 1983-2001 \\
\hline 10 & Waldemar Berardinelli (RJ) & 19 & 5 & 3 & 9 & & 2 & $17(89,5)$ & 1951-1957 \\
\hline 10 & Sérgio Atala Dib (SP) & 19 & 15 & 1 & & 1 & 2 & $3(15,8)$ & 1980-2000 \\
\hline 11 & Fernando Ubatuba (RJ) & 18 & 14 & 4 & & & & $15(83,3)$ & 1957-1962 \\
\hline 12 & Walter Bloise (SP) & 17 & 12 & 1 & 3 & 1 & & $2(11,8)$ & 1978-1994 \\
\hline 13 & José Schermann (RJ) & 16 & 5 & 3 & 7 & & 1 & $11(68,8)$ & 1953-1970 \\
\hline 13 & João Gabriel H. Cordeiro (RJ) & 16 & 4 & 2 & 10 & & & $5(31,3)$ & 1952-1986 \\
\hline 13 & Miriam da Costa Oliveira (RS) & 16 & 11 & 1 & 4 & & & $13(81,3)$ & 1989-2001 \\
\hline 13 & Leila Maria B. Araújo (BA) & 16 & 8 & 2 & 4 & 1 & 1 & $6(37,5)$ & 1979-2001 \\
\hline 14 & Wilian Nicolau (SP) & 15 & 12 & 2 & 1 & & & $2(13,3)$ & 1963-1968 \\
\hline 14 & Marise Lazaretti-Castro (SP) & 15 & 7 & 4 & 3 & 1 & & $3(20,0)$ & 1988-2001 \\
\hline 15 & Isaac Vaissman (RJ) & 14 & 6 & 5 & 3 & & & $8(57,1)$ & $1961-1972$ \\
\hline 15 & Dilson Kamel (RJ) & 14 & 6 & 4 & 4 & & & $2(14,3)$ & 1962-1972 \\
\hline 15 & Antonio Carlos Lerario (SP) & 14 & 4 & 6 & 4 & & & $0(0,0)$ & $1979-2000$ \\
\hline 15 & Rosalinda Y.A. Camargo (SP) & 14 & 9 & 2 & 2 & & 1 & $4(28,6)$ & 1988-2000 \\
\hline
\end{tabular}

(*) Excluídos 32 editoriais (Palavra do Editor) no período compreendido entre 1995 e 2001, por estar ocupando a posição de Editor-chefe. 
Neste quadro 1, pode-se verificar que os autores mais bem posicionados no ranking tinham uma média de 20 autorias no período, embora seu intervalo médio de tempo de contribuição estivesse na faixa dos 10-12 anos, com uma média, portanto, de 1,5 a 2 trabalhos por ano. Evidente que a quantidade de trabalhos submetidos e publicados naquela época era menor do que nos dias de hoje; diversos motivos podem ser alegados, especialmente a periodicidade da revista. Destaca-se, entre os 10 colaboradores melhor colocados, nosso prezado Bernardo Léo Wajchenberg, da Faculdade de Medicina da USP, com 25 trabalhos publicados na revista em 10 anos (1959-1968), com uma média já naquele período de 2,5 autorias/ano. Como ainda hoje sua produtividade é invejável, iremos ver mais adiante que ele se torna o segundo mais importante colaborador dos ABE\&M de todos os tempos.

\section{AS 15 POSICCÕES OCUPADAS PELOS AUTORES MAIS PROFÍCUOS DOS ABE\&M EM TODOS OS TEMPOS (1951-2001)}

No quadro 2. estão apresentados os 30 autores que mais produziram na revista nos seus 50 anos de vida (ou, efetivamente, 45 anos de publicação), compondo um ranking de 15 posições (incluise aqui várias posições de empate, valendo-se apenas do total de autorias como critério, sem outras elaborações).

Nunca é demais lembrar que os autores que mais publicaram nos Arquivos são também frequentes colaboradores em revistas internacionais indexadas, bastando uma consulta ao Medline para verificar este fato.

Encerro este complemento editorial com a certeza de que esta compilação dos autores que mais publicaram na revista merecesse um realce especial e uma homenagem, mas também como um estímulo àqueles que estejam começando sua carreira científica e àqueles que apenas esporadicamente tenham alguma oportunidade de colaborar. A revista é de todos e o conjunto deste material, do autor assíduo ao colaborador eventual, forma a base do conhecimento científico em Endocrinologia e Metabologia desenvolvido no país e continuamente oferecido aos leitores especializados. 